\title{
Comparison between NOD2 gene mutation carriers (3020insC) and non-carriers in breast cancer patients: a clinicopathological and survival analysis
}

\author{
Joanna Huszno ${ }^{1}$, Zofia Kołosza ${ }^{2}$, Karolina Tęcza ${ }^{3}$, Jolanta Pamuła-Piłat ${ }^{3}$, Magdalena Mazur ${ }^{3}$, \\ Ewa Grzybowska ${ }^{3}$
}

\begin{abstract}
${ }^{1}$ Clinical and Experimental Oncology Department, Maria Skłodowska-Curie Memorial Cancer Center and Institute of Oncology, Gliwice Branch, Gliwice, Poland ${ }^{2}$ Biostatistics Unit, Maria Skłodowska-Curie Memorial Cancer Center and Institute of Oncology, Gliwice Branch, Gliwice, Poland

${ }^{3}$ Center for Translational Research and Molecular Biology of Cancer, Maria Sklodowska-Curie Memorial Cancer Center and Institute of Oncology, Gliwice Branch, Gliwice, Poland
\end{abstract}

Submitted: 25 November 2017

Accepted: 2 January 2018

Arch Med Sci Civil Dis 2018; 3: e10-e15

DOI: https://doi.org/10.5114/amscd.2018.73276

Copyright (c) 2018 Termedia \& Banach

\begin{abstract}
Introduction: The 3020insC mutation of NOD2 predisposes to many types of common cancers, e.g. breast cancer. In this report we compare NOD2 3020ins C mutation carriers with non-carriers in a similar age range at diagnosis according to clinicopathological factors and survival in breast cancer patients from the Silesia region in Poland.

Material and methods: We reviewed the medical records of 72 early breast cancer patients, who were diagnosed and treated in $\mathrm{COI}$ in Gliwice. Genetic diagnostics was conducted in all patients. Twenty-eight (39\%) patients were NOD2 mutation carriers and 44 (61\%) were non-carriers.

Results: Triple-negative breast cancer (TNBC) was detected more often in NOD 2 mutation carriers than non-carriers ( $25 \%$ vs. $11.4 \%, p=0.194)$. Similarly, lymph nodes without metastases (NO) were reported more frequently in patients with NOD 2 mutation ( $71.4 \%$ vs. $43.2 \%, p=0.029)$. HER2 without overexpression was observed insignificantly more often in group with NOD2 mutation $(82.1 \%$ vs. $63.6 \%, p=0.115)$. Similarly, lower histological grade $(\mathrm{G} 1+\mathrm{G} 2)$. There was no difference in tumor size $(\mathrm{T} 1-\mathrm{T} 2)(89.3 \%$ vs. $86.4 \%, p=1.00)$ or steroid receptor status $(28.6 \%$ vs. $29.5 \%, p=1.00)$ between groups. The median follow-up was 5.1 years (range: 0.6-26.1 years) for NOD2 carriers and 5.3 years (range: 2.0-19.7 years) for non-carriers. There was no difference between mutation carriers and non-carriers according to overall survival (5-year OS: $96 \%$ vs. 93\%, $p=0.427$ ).

Conclusions: There were no differences between NOD2 (3020insC) mutation carriers and non-carriers, according to comorbid condition, drugs, tumor size, steroid receptor status and 5-year overall survival.
\end{abstract}

Key words: breast cancer, NOD2 mutation carriers, NOD2 non-carriers, clinicopathological factors.

\section{Introduction}

The NOD2 gene has been identified and mapped to chromosome $16 q 12$ by Hugot et al. It consists of 12 exons, and its product, a cyto-

\author{
Corresponding author: \\ Joanna Huszno \\ Clinical and Experimental \\ Oncology Department \\ Maria Skłodowska-Curie \\ Memorial Cancer Center \\ and Institute of Oncology \\ 15 Wybrzeże Armii Krajowej \\ St \\ 44-101 Gliwice, Poland \\ Phone: +48 660726068 \\ E-mail: joahus@wp.pl
}


solic protein, consists of 1,040 amino acids [1]. The NOD2 protein plays an important role in immune system function. It is active in some types of immune system cells (including monocytes, macrophages, and dendritic cells), which help to protect the body against foreign invaders such as viruses and bacteria. The protein is also active in several types of epithelial cells, including Paneth cells, which are found in the lining of the intestine. These cells help to defend the intestinal wall against bacterial infection [2]. NOD2 is involved in the inflammatory response and the activation of the nuclear factor $\kappa \mathrm{B}(\mathrm{NFKB})$ pathway.

At least 17 mutations in the NOD2 gene have been found to cause Blau syndrome, an inflammatory disorder that primarily affects the skin, joints, and eyes. NOD 2 gene mutations can also cause an early-onset sarcoidosis. The mutation predisposes to Crohn's disease, a common chronic inflammatory bowel disease that is known to favor colorectal cancer development [3-6]. Approximately 40 variations in the NOD2 gene have been associated with an increased risk of Crohn's disease.

The 3020insC mutation of NOD2 also predisposes to many types of common cancers, e.g. breast cancer. The mutant allele is more frequently found in women with an early-onset breast cancer and in women with ductal breast cancer with an in situ component. The NOD2 3020insC allele is relatively common $(7.3 \%)$ in the Polish population. The aim of this study was to compare 3020insC NOD2 mutation carriers with non-carriers in a similar age range at diagnosis according to clinicopathological factors and survival.

\section{Material and methods}

A retrospective analysis was conducted on the medical records of 72 breast cancer patients who were diagnosed and treated with chemotherapy, hormone therapy and/or immunotherapy at Maria Sklodowska-Curie Memorial Cancer Center and Institute of Oncology, Gliwice Branch in Poland (COI). The patients were Caucasian women from the southern part of Poland - the Silesian region. Twenty-eight (39\%) of the patients were NOD2 mutation carriers and $44(61 \%)$ of them were non-carriers (control group). The inclusion criterion in the control group was age at diagnosis which was comparable to the age of NOD2 mutation carriers. All patients in the control group were BRCA non-carriers. Genetic diagnostics were conducted in the years 2012-2016. All patients gave written informed consent for genetic examination. The median age at diagnosis of patients was 46 years (range: $27-64$ years). All of them were in good performance status (ZUBROD 0-1). The complete characteristics of patients with regard to demographic and clinicopathological features are presented in Tables I and II.

Table I. Patients' characteristics according to the presence of NOD2 (3020insC) mutation

\begin{tabular}{|c|c|c|c|c|}
\hline Risk factor & $\begin{array}{c}\text { NOD2 mutation } \\
\text { carriers } \\
N=28\end{array}$ & $\begin{array}{c}\text { NOD2 non-carriers } \\
N=44\end{array}$ & OR $(95 \% \mathrm{Cl})$ & $P$-value \\
\hline Age median [years] & $46.0(27-64)$ & $45.5(30-63)$ & & \\
\hline Cigarette smoking: & & & & 0.728 \\
\hline Yes, 9 (12.5\%) & $4(14.3 \%)$ & $5(11.4 \%)$ & $1.3(0.23-6.69)$ & \\
\hline No, 63 (87.5\%) & $24(85.7 \%)$ & $39(88.6 \%)$ & 1 & \\
\hline Comorbid condition: & & & & 0.612 \\
\hline Yes, 23 (31.9\%) & $10(35.7 \%)$ & $13(29.5 \%)$ & $1.32(0.42-4.06)$ & \\
\hline No, 49 (68.1\%) & $18(64.3 \%)$ & $31(70.5 \%)$ & 1 & \\
\hline Diabetes: & & & & 1.00 \\
\hline Yes, 3 (4.2\%) & $1(3.6 \%)$ & $2(4.5 \%)$ & $0.78(0.01-15.68)$ & \\
\hline No, 69 (95.8\%) & 27 (96.4\%) & $42(95.5 \%)$ & 1 & \\
\hline Cardiovascular diseases: & & & & 0.767 \\
\hline Yes, 14 (19.4\%) & $6(21.4 \%)$ & $8(18.2 \%)$ & $1.23(0.31-4.65)$ & \\
\hline No, 58 (80.6\%) & $22(78.6 \%)$ & $36(81.1 \%)$ & 1 & \\
\hline Viral diseases: & & & - & 0.389 \\
\hline Yes, 1 (1.4\%) & $1(3.6 \%)$ & 0 & & \\
\hline No, $71(98.6 \%)$ & 27 (96.4\%) & $44(100 \%)$ & & \\
\hline
\end{tabular}


Table II. Cancers in family history according to presence of NOD2 (3020insC) mutation carriers

\begin{tabular}{|c|c|c|c|c|}
\hline Risk factor & $\begin{array}{c}\text { NOD } 2 \text { mutation } \\
\text { carriers } \\
N=28\end{array}$ & $\begin{array}{c}\text { NOD2 non-carriers } \\
N=44\end{array}$ & OR $(95 \% \mathrm{Cl})$ & $P$-value \\
\hline \multicolumn{2}{|c|}{ Breast cancer in family history: } & & & 0.178 \\
\hline Yes, 19 (26.4\%) & $10(35.7 \%)$ & $9(20.5 \%)$ & $2.16(0.65-7.17)$ & \\
\hline No, 53 (73.6\%) & $18(64.3 \%)$ & $35(79.5 \%)$ & 1 & \\
\hline \multicolumn{2}{|c|}{ Renal cancer in family history: } & & & 0.389 \\
\hline Yes, 1 (1.4\%) & $1(3.6 \%)$ & 0 & - & \\
\hline No, 71 (98.6) & $27(96.4 \%)$ & $44(100 \%)$ & & \\
\hline \multicolumn{2}{|c|}{ Lung cancer in family history: } & & & 0.698 \\
\hline Yes, 7 (9.7\%) & $2(7.1 \%)$ & $5(11.4 \%)$ & $0.6(0.05-4.04)$ & \\
\hline No, 65 (90.3\%) & $26(92.9 \%)$ & $39(88.6 \%)$ & 1 & \\
\hline \multicolumn{2}{|c|}{ Gynecological cancer in family history: } & & & 0.235 \\
\hline Yes, 7 (9.7\%) & $1(3.6 \%)$ & $6(13.6 \%)$ & $0.23(0.00-2.14)$ & \\
\hline No, 65 (90.3\%) & $27(96.4 \%)$ & $38(86.4 \%)$ & 1 & \\
\hline \multicolumn{2}{|c|}{ Gastrointestinal cancer in family history: } & & & 0.373 \\
\hline Yes, 14 (19.4\%) & $7(25 \%)$ & $7(15.9 \%)$ & $1.76(0.45-6.76)$ & \\
\hline No, 58 (80.6\%) & $21(75 \%)$ & $37(84.1 \%)$ & 1 & \\
\hline \multicolumn{2}{|l|}{ Larynx cancer: } & & & 0.518 \\
\hline Yes, 2 (2.8\%) & 0 & $2(4.5 \%)$ & $0(0-3.03)$ & \\
\hline No, 70 (97.2\%) & $28(100 \%)$ & $42(95.5 \%)$ & 1 & \\
\hline \multicolumn{2}{|c|}{ Cancer in family history: } & & & 0.809 \\
\hline Yes, 42 (58.3\%) & $17(60.7 \%)$ & $25(56.8 \%)$ & $1.17(0.40-3.47)$ & \\
\hline No, 30 (41.7\%) & $11(39.3 \%)$ & 19 (43.2\%) & 1 & \\
\hline
\end{tabular}

Anthracycline-based chemotherapy was applied to 37 (51.4\%) patients. Nineteen $(26.4 \%)$ of the women received anthracycline and taxanes together (at the same time or taxanes after anthracyclines). Sixteen (22.2\%) patients had no systemic treatment. Adjuvant and neoadjuvant therapy were given to 32 (44.5\%) and 24 (33.3\%) in the whole group, respectively. Trastuzumab was administered to patients with tumor HER2 (human epidermal growth factor) overexpression. All women with positive steroid receptor status (estrogen (ER), progesterone receptor (PR)) received hormone therapy $(53,73.6 \%$ of patients). Radiotherapy was applied to 49 (61\%) including all patients after breast preserving treatment. Treatment strategies are presented in Table III. The analysis of patients' medical records was performed according to the national legal regulation.

All patients were tested for the presence of 3020insC mutation of NOD2. Mutation analysis was carried out by a multiplex allele-specific polymerase chain reaction assay. Each patient signed informed consent before venous blood collection for a genetic test. Genomic DNA was isolated from peripheral blood leucocytes.

\section{Statistical analysis}

Statistical analysis was carried out using Statistica 7 software. The qualitative features were presented as the percentage of their occurrence and evaluated with Fisher's test and the $\chi^{2}$ test with Yates' correction. Odds ratios (ORs) and 95\% confidence intervals ( $95 \% \mathrm{Cls}$ ) were calculated as measures of association between the analyzed factors and the presence of NOD2 mutation. Overall survival was estimated using the Kaplan-Meier method. The differences were considered significant if the $p$-value was $\leq 0.05$.

\section{Results}

We analyzed a group of 72 breast cancer patients (28 NOD2 mutation carriers and 44 non-carriers). The median age at breast cancer diagnosis 
Table III. Treatment strategies according to presence of NOD2 (3020insC) mutation

\begin{tabular}{|lccc|}
\hline Risk factor & NOD2 mutation carriers, $\boldsymbol{N}=\mathbf{2 8}$ & NOD2 non-carriers, $\boldsymbol{N}=\mathbf{4 4}$ & $P$-value \\
\hline $\begin{array}{l}\text { Radiotherapy: } \\
\text { Yes, } 49(68.1 \%)\end{array}$ & $20(71.4 \%)$ & $29(65.9 \%)$ & 0.796 \\
\hline No, $23(31.9 \%)$ & $8(28.6 \%)$ & $15(34.1 \%)$ & \\
\hline \begin{tabular}{l} 
Hormone therapy \\
\hline Yes, $53(73.6 \%)$
\end{tabular} & $20(71.4 \%)$ & $33(75 \%)$ & 0.788 \\
\hline No, $19(26.4 \%)$ & $8(28.6 \%)$ & $11(25 \%)$ & \\
\hline \begin{tabular}{l} 
Chemotherapy \\
\hline Yes, $56(77.8 \%)$
\end{tabular} & $19(67.9 \%)$ & $37(84.1 \%)$ & 0.147 \\
\hline No, $16(22.2 \%)$ & $9(32.1 \%)$ & $7(15.9 \%)$ & \\
\hline
\end{tabular}

was 46.0 (27-64) years for the carriers of the NOD2 mutation and 45.5 (30-63) years for non-carriers. There was no difference between these two groups in cigarette smoking $(14.3 \%$ vs. $11.4 \%, p=0.728$ $\mathrm{OR}=1.3)$. Co-morbid conditions were observed in $35.7 \%$ of patients with NOD2 mutation and $29.5 \%$ of patients without mutation ( $p=0.612$; OR = 1.32). Similarly, there was no association between the presence of mutation and cardiovascular diseases $(21.4 \%$ vs. $18.2 \%, p=0.767$; OR $=1.23)$ or diabetes (3.6\% vs. $4.5 \%, p=1.00$; OR $=0.78$ ) or viral diseases (3.6\% vs. $0, p=0.389$ ) (Table I).

Cancer in family history was reported in $60.7 \%$ of NOD2 mutation carriers and in $56.8 \%$ of non-carriers, $p=0.809$; $\mathrm{OR}=1.17$. The presence of breast cancer $(35.7 \%$ vs. $20.5 \%, p=0.178$; OR = $2.16)$, renal cancer ( $3.6 \%$ vs. $0, p=0.389$ ) and gastrointestinal cancers ( $25 \%$ vs. $15.9 \%, p=0.373$, OR $=1.76$ ) were detected insignificantly more often in family history of NOD2 mutation carriers in comparison to non-carriers. In contrast, lung (11.4\% vs. $7.1 \%, p=0.698$; $\mathrm{OR}=0.6)$, gynecological cancers $(13.6 \%$ vs. $3.6 \%, p=0.235$; OR $=0.23)$ and larynx cancer ( $4.5 \%$ vs. $0, p=0.518$ ) were described insignificantly more often in non-carriers (Table II).

Triple-negative breast cancer (TNBC) tumors were detected insignificantly more often in NOD2 mutation carriers than non-carriers ( $25 \%$ vs. $11.4 \%$, $p=0.194 ; \mathrm{OR}=2.6)$. Similarly, lymph nodes without metastases (N0) were reported more frequently in patients with NOD2 mutation in comparison to non-carriers $(71.4 \%$ vs. $43.2 \%, p=0.029$; OR = $0.30)$. Most patients had tumors of a lower grade, T1-T2 (87.5\%). There was no difference in tumor size between groups (T1-T2) (89.3\% vs. $86.4 \%$, $p=1.00 ; \mathrm{OR}=0.76)$. HER2 without overexpression was observed insignificantly more often in NOD2 mutation carriers ( $82.1 \%$ vs. $63.6 \%, p=0.115$; $\mathrm{OR}=0.38)$. In contrast, there were no differences between mutation carriers and non-carriers according to $\mathrm{ER}(28.6 \%$ vs. $29.5 \%, p=1.00$; OR =
$1.05)$ and $\mathrm{PR}(32.1 \%$ vs. $27.3 \%, p=0.791 ; \mathrm{OR}=$ $0.79)$ negative steroid receptor status. The lobular type of breast cancer was observed insignificantly more often in NOD2 mutation carriers $(7.1 \%$ vs. $4.5 \%)$. Most patients in both groups had ductal invasive carcinoma. Lower histological grade $(\mathrm{G} 1+\mathrm{G} 2)$ was observed insignificantly more frequently in NOD2 mutation carriers than non-carriers $(78.6 \%$ vs. $63.6 \%, p=0.202$; OR $=0.48)$. Grade 3 were detected in $21.4 \%$ of mutation carriers and $36.4 \%$ of non-carriers. Pathological characteristics of the tumors according to the presence of NOD2 mutation are shown in Table IV.

All the patients were followed up in the Cancer Center and Institute of Oncology in Gliwice. The median follow-up was 5.1 years (range: 0.6-26.1 years) for NOD2 carriers and 5.3 years (range: 2.019.7 years) for non-carriers. There was no difference between mutation carriers and non-carriers in overall survival ( 5 years OS: $96 \%$ vs. $93 \%, p=$ $0.427)$. In the case of contralateral breast cancer the follow-up was counted from the date of the first diagnosis of breast cancer. Second primary cancers were found in four patients: in three NOD2 mutation carriers (2 patients with breast cancer and one patient with endometrial cancer) and in one patient in the control group (lung cancer).

\section{Discussion}

In the present study, we compare NOD2 mutation carriers and non-carriers according to clinicopathological factors such as hormone status (estrogen (ER), progesterone receptor (PR)), human epidermal growth factor (HER2), tumor size, the presence of lymph node metastases, co-morbid conditions and history of cancer in the family.

The NOD2 3020insC allele is relatively common (7.3\%) in the Polish population [7]. In a previous study it was reported in $8.0 \%$ of 462 breast cancer patients from Szczecin [8] and in $8.8 \%$ of 148 
Joanna Huszno, Zofia Kołosza, Karolina Tęcza, Jolanta Pamuła-Piłat, Magdalena Mazur, Ewa Grzybowska

Table IV. Pathological characteristics of tumors according to presence of NOD2 (3020insC) mutation

\begin{tabular}{|c|c|c|c|c|}
\hline Risk factor & $\begin{array}{c}\text { NOD } 2 \text { mutation } \\
\text { carriers } \\
N=28\end{array}$ & $\begin{array}{c}N O D 2 \\
\text { non-carriers } \\
N=44\end{array}$ & OR $(95 \% \mathrm{Cl})$ & $P$-value \\
\hline Clinical staging nodes: & & & & 0.029 \\
\hline N positive, 33 (45.8\%) & $8(28.6 \%)$ & $25(56.8 \%)$ & $0.30(0.10-0.93)$ & \\
\hline N0, 39 (54.2\%) & $20(71.4 \%)$ & 19 (43.2\%) & 1 & \\
\hline Tumor size: & & & & 1.00 \\
\hline T3-4, 9 (12.5\%) & $3(10.7 \%)$ & $6(13.6 \%)$ & $0.76(0.11-3.98)$ & \\
\hline T1-2, 63 (87.5\%) & 25 (89.3\%) & $38(86.4 \%)$ & 1 & \\
\hline Grade G: & & & & 0.202 \\
\hline G3, 22 (30.6\%) & $6(21.4 \%)$ & $16(36.4 \%)$ & $0.48(0.13-1.57)$ & \\
\hline $\mathrm{G} 1+\mathrm{G} 250$ (69.4\%) & $22(78.6 \%)$ & $28(63.6 \%)$ & 1 & \\
\hline ER: & & & & 1.00 \\
\hline Positive, 51 (70.8\%) & $20(71.4 \%)$ & $31(70.5 \%)$ & $1.05(0.33-3.48)$ & \\
\hline Negative, 21 (29.2\%) & $8(28.6 \%)$ & $13(29.5 \%)$ & 1 & \\
\hline PR: & & & & 0.791 \\
\hline Positive, 51 (70.8\%) & $19(67.9 \%)$ & $32(72.7 \%)$ & $0.79(0.25-2.57)$ & \\
\hline Negative, 21 (29.2\%) & $9(32.1 \%)$ & $12(27.3 \%)$ & 1 & \\
\hline HER2 overexpression: & & & & 0.115 \\
\hline Positive, 21 (29.2\%) & $5(17.9 \%)$ & $16(36.4 \%)$ & $0.38(0.10-1.32)$ & \\
\hline Negative, 51 (70.8\%) & $23(82.1 \%)$ & $28(63.6 \%)$ & 1 & \\
\hline Triple negative: & & & & 0.194 \\
\hline Yes, 12 (16.7\%) & 7 (25\%) & $5(11.4 \%)$ & $2.6(0.61-11.61)$ & \\
\hline No, 60 (83.3\%) & $21(75 \%)$ & $39(88.6 \%)$ & 1 & \\
\hline Histological type: & & & & 0.622 \\
\hline Ductal invasive carcinoma, 59 (81.9\%) & $24(85.7 \%)$ & $35(79.5 \%)$ & 1 & \\
\hline Lobular invasive carcinoma, 4 (5.6\%) & $2(7.1 \%)$ & $2(4.5 \%)$ & $1.46(0.19-11.08)$ & \\
\hline Other, 9 (15.9\%) & $2(7.1 \%)$ & $7(15.9 \%)$ & $0.42(0.08-2.18)$ & \\
\hline Luminal B type, 29 (40.3\%) & $8(28.6 \%)$ & $21(47.7 \%)$ & 1 & 0.099 \\
\hline Luminal A type, 24 (33.3\%) & $12(42.9 \%)$ & $12(27.3 \%)$ & $2.63(0.84-8.22)$ & \\
\hline Triple negative, 12 (16.7\%) & $7(25 \%)$ & $5(11.4 \%)$ & $3.68(0.90-15.01)$ & \\
\hline Non-luminal, 7 (9.7\%) & $1(3.6 \%)$ & $6(13.6 \%)$ & $0.44(0.05-4.23)$ & \\
\hline
\end{tabular}

breast cancer patients from Bydgoszcz [9]. The population risk of breast cancer before the age of 50 , associated with the NOD2 mutation, is approximately $1 \%$ [8]. In the present study, the mutation was detected in 28 women, reaching the incidence of $6.1 \%$.

The presence of the NOD2 3020insC allele increases the lifetime risk of cancer by approximately $25 \%$ to $35 \%$ [7]. In the study conducted by Huzarski et al., the authors found a modest, not statistically significant, association of the NOD2 3020insC mutation with family history of breast cancer [8]. Janiszewska et al. suggested that the NOD2 3020insC mutation might predominantly increase the risk of developing digestive tract cancer rather than breast cancer [9]. In a study conducted by Kurzawski et al. the frequency of the 3020ins $C$ mutation in a consecutive series of 250 non-hereditary nonpolyposis colorectal cancer patients $>50$ years of age was significantly elevated compared to the control population (OR $=2.23 ; p=0.0046$ ) [10]. Teodorczyk et al. showed that for NOD2 3020insC carriers over 50 years of age the risk of gastric cancer more than doubled 
$(\mathrm{OR}=2.479, p=0.022)$ and among women almost trebled [11]. In our analysis, the presence of breast cancer $(35.7 \%$ vs. $20.5 \%, p=0.178$; OR $=2.16)$, renal cancer ( $3.6 \%$ vs. $0, p=0.389)$ and gastrointestinal cancers $(25 \%$ vs. $15.9 \%, p=0.373$, OR = 1.76) were detected insignificantly more often in family history of NOD2 mutation carriers in comparison to non-carriers.

In some studies there was observed an association between NOD2 mutation and early breast cancer $(O R=1.9 ; p=0.01)$ [8]. Similarly, ductal invasive carcinoma breast cancer with an in situ component was more often reported in mutation carriers $(\mathrm{OR}=2.2 ; p=0.006)$ [8]. In our group all patients had early breast cancer. No significant difference was found between NOD2 mutation carriers and non-carriers according to the presence of ductal invasive carcinoma (85.7\% vs. $79.5 \%$ ). The lobular type of breast cancer was observed insignificantly more often in NOD2 mutation carriers $(7.1 \%$ vs. $4.5 \%)$. The other clinicopathological factors were also analyzed. Janiszewska et al. did not find any NOD2 mutation in patients diagnosed with breast cancer after the age of 50 years. The median age at breast cancer diagnosis in our patients was 46.0 (27-64) years for carriers of the NOD2 mutation and 45.5 years (30-63) for non-carriers. We did not observe a difference according to age between the groups due to the selection of the control group (in a similar age range at diagnosis as NOD2 mutation carriers). The other factors associated with NOD2 mutation in our study are: HER2 negative tumors (HER2-), lymph nodes without metastases $(\mathrm{N}-)$ and lower histological grade $(<G 3)$, which is in agreement with our previous results [12].

In conclusion, there were no differences between NOD2 (3020insC) mutation carriers and non-carriers according to comorbid condition, drugs, tumor size, steroid receptor status and 5 -year overall survival. The presence of NOD2 mutation was found to be associated with an increased risk of breast, renal and colorectal cancer in family history. NOD2 mutation in breast cancer women was associated with lymph nodes without metastasis (NO), lower histological grade $(\mathrm{G}<3)$ and negative HER2 receptor status (HER2-).

\section{Conflict of interest}

The authors declare no conflict of interest.

\section{References}

1. Hugot JP, Laurent-Puig P, Gower-Rousseau C, et al. Mapping of a susceptibility locus for Crohn's disease on chromosome 16. Nature 1996; 29: 821-3.

2. Inohara N, Nuñez G. NODs intracellular proteins involved in inflammation and apoptosis. Nat Rev Immunol 2003; 3: 371-82.
3. Zeybek C, Basbozkurt G, Gul D, Demirkaya E, Gok F. A new mutation in Blau syndrome. Case Rep Rheumatol 2015; 2015: 463959.

4. Ogura Y, Bonen DK, Inohara N, et al. A frameshift mutation in NOD2 associated with susceptibility to Crohn's disease. Nature 2001; 411: 603-6.

5. Hampe J, Cuthbert A, Croucher PJ, et al. Association between insertion mutation in NOD2 gene and Crohn's disease in German and British populations. Lancet 2001; 357: 1925-8.

6. Branquinho D, Freire P, Sofia C. NOD2 mutations and colorectal cancer - Where do we stand? World J Gastrointest Surg 2016; 8: 284-93.

7. Lubiński J, Huzarski T, Kurzawski G, et al. The 3020insC allele of NOD2 predisposes to cancer of multiple organs. Hered Cancer Clin Practice 2005; 3: 59-63.

8. Huzarski T, Lener M, Domagala W, et al. The 3020insC allele of NOD2 predisposes to early-onset breast cancer. Breast Cancer Res Treat 2005; 89: 91-3.

9. Janiszewska H, Haus O, Lauda-Swieciak A, et al. The NOD2 3020insC mutation in women with breast cancer from the Bydgoszcz region in Poland. First results. Hered Cancer Clin Pract 2006; 4: 15-9.

10. Kurzawski G, Suchy J, Kładny J, et al. The NOD2 3020insC mutation and the risk of colorectal cancer. Cancer Res 2004; 64: 1604-6.

11. Teodorczyk U, Cybulski C, Jakubowska A, et al. Mutations and polymorphisms of genes moderate increase in gastric cancer risk. Cancer Clin Pract 2012; 10 (Suppl 3): A22.

12. Huszno J, Grzybowska E, Kołosza Z, et al. The 3020insc allele of the NOD2 gene in breast cancer patients a clinicopathological analysis. Int J Res Stud Med Health Sci 2017; 2: 3-7. 